\title{
Patient-Physician Agreement in Reporting and Prioritizing Existing Chronic Conditions
}

\author{
Stéphanie Sidorkiewicz ${ }^{1,2}$ \\ Alexandre Malmartel 1,2 \\ Lea Prevost ${ }^{1}$ \\ Henri Partouche ${ }^{1}$ \\ Juliette Pinot ${ }^{1}$ \\ Armelle Grangé-Cabane ${ }^{1}$ \\ Céline Buffel du Vaure', \\ Serge Gilberg ${ }^{1}$
}

'Department of General Medicine, Paris

Descartes University, Paris, France

${ }^{2}$ METHODS Team, Centre of Research in Epidemiology and Statistics Sorbonne Paris Cité (CRESS), INSERM, UMR 1153, Paris, France

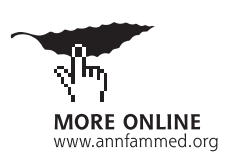

Conflicts of interest: autbors report none.

\section{CORRESPONDING AUTHOR}

Stéphanie Sidorkiewicz Département de Médecine Générale

Université Paris Descartes

24 Rue du Faubourg Saint-Jacques

75014 Paris, France

stephanie.sidorkiewicz@parisdescartes.fr

\begin{abstract}
PURPOSE In this study, we aimed to assess (1) the agreement between patient self-reports and general practitioner (GP) reports of the chronic conditions affecting the patients and (2) the agreement between patients and GPs on health priorities in a primary care setting.
\end{abstract}

METHOD Patients were recruited in the Parisian area of France by a convenience sample of GPs; eligibility criteria required that the GP was the patient's listed primary care provider for at least 12 months. Participants were asked to report all the patient's current chronic conditions by using a previously developed list of 124 chronic conditions and write a list of up to 3 priority conditions.

RESULTS From April to May 2017, 233 patients were recruited from 16 GP practices. Agreement between the number of conditions reported by patients and by GPs was moderate (intraclass correlation coefficient $0.59,95 \% \mathrm{Cl}, 0.50$ to 0.69 ). Agreement between patient self-reports and GP reports of each chronic condition ranged from very good (eg, $\kappa=0.85$ for hypothyroidism) to poor (eg, $\kappa=0.12$ for chronic anxiety disorder). Among the 153 patient-GP pairs for which both the patient and GP wrote a priority list, 45 (29.4\%) of patients' first priorities did not appear anywhere on the corresponding GPs' lists, and 19 (12.4\%) pairs had no matching priority condition.

CONCLUSIONS Agreement between patients and their GPs varied widely depending on the diseases reported. Low agreement on health priorities suggests a need for improvement to ensure better alignment between patient and physician perspectives.

Ann Fam Med 2019;17:396-402. https://doi.org/10.1370/afm.2444.

\section{BACKGROUND}

$\mathrm{T}$ he aging of the population and improvement of health care have led to increased prevalence of chronic conditions. More than $40 \%$ of adults in high-income countries have at least 1 chronic condi-

tion. ${ }^{1}$ Chronic diseases increase health care utilization and health care expenditures $^{2-4}$ and change the nature of care for both physicians and patients. ${ }^{5,6}$ Physicians face challenges of care coordination and prioritization, ${ }^{7,8}$ while patients face challenges of navigating through complex health care pathways, burden of treatment, ${ }^{6-9}$ and altered quality of life. ${ }^{10}$ To address these new challenges, current research emphasizes that the patient's preferences should be included in the decision-making process ${ }^{11}$ and that care should evolve from disease orientation to patient goal orientation. ${ }^{7,12}$ This increased promotion of patient-centered care may require a shift in how physicians engage their patients in care.

Good communication between patients and physicians is the first step in the process of patient involvement in health care. ${ }^{11}$ In the literature, good agreement between patients and physicians may reflect how effective this communication is. ${ }^{13,14}$ Good agreement on diagnosis and treatment is associated with higher patient satisfaction and positive health outcomes ${ }_{1}^{15}$ and good agreement about problems is associated with better outcomes as perceived by patients. ${ }^{16}$ Some studies have previously 
described the level of agreement between patients and physicians on patients' chronic conditions, but little is known about the extent to which they agree regarding care prioritization, except in very specific fields. ${ }^{17}$ Most published studies focused on agreement about highly prevalent diseases ${ }^{17-21}$ or described patients with a specific disease ${ }^{17,22,23}$ or multimorbid patients. ${ }^{24,25}$ Furthermore, some authors highlighted that such comparisons may depend on the health care system. ${ }^{18}$

In France, the health care system centers on primary care: patients are encouraged to be listed with a general practitioner (GP) of their choice, and GPs are supposed to receive all relevant medical reports about their patients and coordinate specialist care. Thus, we hypothesized that French GPs should have a good knowledge of their patients' diseases but might show discrepancies with their patients concerning the prioritization of care.

Therefore, we aimed to apply an original method inspired by previous studies ${ }^{17,19}$ by conducting the first exploratory study in a French primary care setting and focusing on a large range of chronic conditions. In our study, we aimed to assess the agreement between patient self-reported and GP-reported chronic conditions affecting patients and the agreement between patients and GPs on health priorities (ie, the most important conditions to manage or care for according to patients and GPs).

\section{METHODS}

We designed a cross-sectional observational study using self-reported questionnaires among patients and their GPs in a primary care setting.

\section{Setting and Participants}

The patients were recruited in the Parisian area of France by a convenience sample of 16 GPs affiliated with the Department of Family Medicine of Paris Descartes University. We included patients aged $\geq 18$ years; the GP had to be listed as patient's primary care provider for $\geq 12$ months. We excluded patients with cognitive impairment, visual impairment preventing the completion of the questionnaire, or language barrier. All patients provided written consent to participate. The study protocol was approved by the Institutional Review Board CPP Nord Ouest IV (no. 17/29).

\section{Recruitment Procedure}

Recruitment took place during a randomly selected half-day per week over 4 weeks. During the recruitment half-day, GPs were asked to check the eligibility of all scheduled patients and complete the study questionnaire before starting a consultation with an eligible patient by reviewing the patient's medical record. At the end of the consultation, the GP invited the patient to participate in the study by giving the patient a consent form, a questionnaire, and a return envelope. The questionnaires were anonymous and preidentified with a number for each patient-GP pair. The GPs were not allowed to change their answers after beginning a consultation and had no access to patients' answers.

\section{Data Collection}

Both the patient and GP questionnaires contained 3 parts: sociodemographic questions, a list of chronic conditions, and an open-ended question about the patient's 3 most important chronic conditions.

\section{Development of a List of Chronic Conditions}

We first developed a list of chronic conditions during a preliminary study (the complete procedure is detailed in Supplemental Figure 1). Briefly, we selected a preliminary list of chronic conditions based on the French version of the International Classification of Primary Care, 2nd Ed. ${ }^{26}$ We then conducted a 2-stage modified Delphi online survey with a network of GPs having expertise in multimorbidity to prioritize items to build consensus for the list. ${ }^{27,28}$ During the Delphi process, GPs were asked to rate 383 conditions on a 9-point scale ( $1=$ not relevant at all, $9=$ extremely relevant). After 2 Delphi rounds and in-person meetings, the workgroup reached consensus on a list of 124 chronic conditions (Supplemental Table 1).

Patient \& GP Reports of Patients' Chronic Conditions Both the patient and GP questionnaires contained the list of the 124 selected conditions presented in the same fixed order. We first defined the concept of "chronic condition" by using the same wording for patients and GPs: "A chronic disease or chronic condition is a health condition that requires regular health care or monitoring (visits, medications, physical therapy, monitoring, diet, etc) during 6 months or more. ${ }^{.29}$ Participants were then asked to report all current chronic conditions they [patient] or their patient [physician] had, with the following instruction: "From the list below, please check all your [patient]/all the patient's [physician] chronic health conditions." At the end of the list, the questionnaire proposed 2 additional possible responses: "Other" (with dedicated space to write free text) and "I do [patient]/The patient does [physician] not have any chronic condition."

\section{Patient and GP Prioritization of Patients' Chronic Conditions}

Both patients and physicians were asked to answer the same open-ended question about their care prioritiza- 
tion: "Among your [the patient's] chronic conditions, can you tell us which are, in your opinion, the most important to manage or care for?" The participants were asked to write a priority list of up to 3 chronic conditions and to rank them from 1 (most important) to 3 .

\section{Statistical Analysis}

Descriptive data are described with numbers (percentages) for categorical variables and means (SD) or medians (interquartile range [IQR]) for quantitative variables.

\section{Agreement Between Patient-Reported} and GP-Reported Chronic Conditions in Patients For each chronic condition on the list, we calculated its prevalence according to patient self-reports and GP reports. The free-text answers were reclassified independently by 2 researchers (L.P. and S.S.) who used existing items on the list when appropriate (eg, "cholesterol" was reclassified with the existing item "dyslipidemia") or the category "other condition" otherwise. The agreement on the number of chronic conditions was assessed by the intraclass correlation coefficient (ICC), ${ }^{30}$ given that the number of conditions was assessed on a continuous scale. Specific agreement between patient self-reports and GP reports of each chronic condition was assessed by Cohen's $\mathrm{K}$ coefficient, ${ }^{31}$ given that this outcome was a binary rating (presence or absence of the disease). The 95\% confidence intervals (CIs) were determined by a bootstrap method to account for the clustered structure of our data (several patients evaluated by the same physician).

\section{Agreement Between Patients and GPs on Health Priorities}

Three researchers (A.M., J.P., and S.S.) independently classified the conditions in the priority lists by using the method described above. To describe the level of agreement between patient priorities and GP priorities, we first calculated the number (\%) of patient-GP pairs with no matching chronic condition vs at least 1 matching condition in their priority list and the number (\%) of patient-GP pairs with the presence of the patient's top priority list in the corresponding GP's list. We then calculated the number (\%) of priority chronic conditions reported: only in the patient priority list, only in the GP priority list, or in both the patient and GP priority lists. For example, for a given patient-GP pair, if the patient listed 2 chronic conditions (A and $\mathrm{B}$ ) and if the corresponding GP listed 3 chronic conditions ( $\mathrm{B}, \mathrm{C}$, and $\mathrm{D})$, we considered that 4 priority chronic conditions in total had been reported (A, B, C, and D): 1 condition only in the patient's priority list (A), 2 only in the GP's priority list (C and D), and 1 in both the patient and GP lists (B).

\section{RESULTS}

From April to May 2017, 233 patients (75.5\% of patients who were invited to participate) were recruited from a convenience sample of 16 GP practices. The median age was 59 years (IQR 41.0-72.0), and 139 were women (59.7\%) (Table 1). Eligible patients who were not included in the study were not statistically different from those included in terms of sex $\left(\chi^{2}, P=.52\right)$ and age ( $t$ test, $\left.P=.08\right)$. The characteristics of the 16 participating GPs are detailed in Supplemental Table 2.

\section{Agreement Between Patient Self-Reports and GP Reports of Patients' Chronic Conditions}

The mean number of chronic conditions reported by patients and GPs was $3.8(\mathrm{SD}=3.1)$ and $3.4(\mathrm{SD}=2.5)$, respectively. A total of 182 patients (78.1\%) reported having 2 or more conditions (ie, multimorbidity) vs 184 (79.0\%) according to the GPs. Agreement between the number of conditions reported by patients and GPs was moderate (ICC $0.59,95 \%$ CI, 0.49 to 0.68 ). The 3 most frequently reported conditions by both patients and GPs were high blood pressure $(34.3 \%$ and $38.6 \%$, respectively), osteoarthritis ( $25.3 \%$ and $18.0 \%)$, and chronic anxiety disorder (14.2\% and $13.7 \%$ ) (Table 2).

Agreement between patients and GPs regarding each reported chronic condition ranged from very good to poor depending on the condition. According to the Altman classification, ${ }^{32}$ agreement was very

Table 1. Patient Characteristics $(n=233)$

\begin{tabular}{|c|c|}
\hline Characteristics & Value \\
\hline Age, median (IQR), y & $59(41.0-72.0)$ \\
\hline Female sex, $\mathrm{n}(\%)$ & $139(59.7)$ \\
\hline \multicolumn{2}{|l|}{ Marital status, ${ }^{a}$ n (\%) } \\
\hline Single, never married & $50(21.5)$ \\
\hline Married or domestic partnership & $137(58.8)$ \\
\hline Divorced or separated & $25(10.7)$ \\
\hline Widowed & $15(6.4)$ \\
\hline \multicolumn{2}{|l|}{ Level of education, ${ }^{\mathrm{b}} \mathrm{n}(\%)$} \\
\hline Primary school & $10(4.3)$ \\
\hline Secondary school & $50(21.5)$ \\
\hline High school graduate & $29(12.4)$ \\
\hline Bachelor's degree & $46(19.7)$ \\
\hline $\begin{array}{l}\text { Master's degree or other advanced } \\
\text { degree beyond a master's degree }\end{array}$ & $84(36.1)$ \\
\hline Other & $7(3.0)$ \\
\hline Patients with ALD status, ${ }^{c}$ n (\%) & $87(37.3)$ \\
\hline \multicolumn{2}{|l|}{$\mathrm{QQR}=$ interquartile range. } \\
\hline \multicolumn{2}{|c|}{$\begin{array}{l}\text { 'ALD status is a French medico-administrative program that refers to a list of } \\
\text { recognized chronic illnesses (affections de longue durée [ALDs]). Patients with } \\
\text { ALD status are covered at } 100 \% \text { by the French Social Security for expenditures } \\
\text { related to their disease. }\end{array}$} \\
\hline
\end{tabular}


Table 2. Agreement Between Patient Self-Reports and General Practitioner (GP) Reports of Patients' Chronic Conditions ( $n=233$ Patient-GP Pairs)

\begin{tabular}{|c|c|c|c|c|c|c|c|}
\hline \multirow[b]{2}{*}{$\begin{array}{l}\text { Chronic } \\
\text { condition }^{a}\end{array}$} & \multirow[b]{2}{*}{$\begin{array}{c}\text { Patient Report } \\
\text { n (\%) } 95 \% \text { Cl }\end{array}$} & \multirow[b]{2}{*}{$\begin{array}{c}\text { GP Report } \\
\text { N (\%) } 95 \% \text { CI }\end{array}$} & \multicolumn{4}{|c|}{ Patient-GP Agreement ${ }^{b}$} & \multirow{2}{*}{$\begin{array}{l}\text { Agreement } \\
\text { Statistic } \\
\kappa(95 \% \mathrm{Cl})\end{array}$} \\
\hline & & & $\begin{array}{l}\text { Patient-, } \\
\text { GP- }\end{array}$ & $\begin{array}{l}\text { Patient }+ \text {, } \\
\text { GP- }\end{array}$ & $\begin{array}{l}\text { Patient-, } \\
\text { GP+ }\end{array}$ & $\begin{array}{l}\text { Patient+, } \\
\text { GP+ }\end{array}$ & \\
\hline Osteoarthritis & 59 (25.3) [19.7-30.9] & 42 (18.0) [13.1-22.9] & 157 & 34 & 17 & 25 & $0.36(0.25-0.46)$ \\
\hline $\begin{array}{l}\text { Chronic anxiety } \\
\text { disorder }\end{array}$ & 33 (14.2) [9.7-18.7] & 32 (13.7) [9.2-18.1] & 176 & 25 & 24 & 8 & $0.12(0.00-0.30)$ \\
\hline $\begin{array}{l}\text { Chronic sleeping } \\
\text { disorder }\end{array}$ & 33 (14.2) [9.7-18.7] & 7 (3.0) [0.8-5.2] & 197 & 29 & 3 & 4 & $0.16(0.00-0.32)$ \\
\hline $\begin{array}{l}\text { Chronic low-back } \\
\text { pain }\end{array}$ & $32(13.7)[9.2-18.1]$ & $29(12.4)[8.2-16.7]$ & 183 & 21 & 18 & 11 & $0.26(0.03-0.42)$ \\
\hline $\begin{array}{l}\text { Gastroesophageal } \\
\text { reflux disease or } \\
\text { chronic gastritis }\end{array}$ & $31(13.3)[8.9-17.7]$ & $32(13.7)$ [9.2-18.1] & 186 & 15 & 16 & 16 & $0.43(0.29-0.53)$ \\
\hline $\begin{array}{l}\text { Hearing impairment } \\
\text { or presbycusis }\end{array}$ & 27 (11.6) [7.5-15.7] & 7 (3.0) [0.8-5.2] & 205 & 21 & 1 & 6 & $0.32(0.03-0.56)$ \\
\hline $\begin{array}{l}\text { Chronic rhinitis or } \\
\text { sinusitis }\end{array}$ & $25(10.7)[6.7-14.7]$ & $17(7.3)[4.0-10.6]$ & 200 & 16 & 8 & 9 & $0.37(0.23-0.51)$ \\
\hline Asthma & $24(10.3)[6.4-14.2]$ & $18(7.8)[4.5-11.2]$ & 203 & 12 & 6 & 12 & $0.53(0.35-0.71)$ \\
\hline Tobacco use & $22(9.4)$ [5.7-13.1] & $25(10.7)$ [6.7-14.7] & 201 & 7 & 10 & 15 & $0.60(0.46-0.74)$ \\
\hline
\end{tabular}

good for hypothyroidism $(\kappa=0.85)$, good for diabetes $(\kappa=0.70)$ or high blood pressure $(\kappa=0.74)$, moderate for asthma $(\kappa=0.53)$ or obesity $(\kappa=0.45)$, fair for osteoarthritis $(\kappa=0.36)$ or eczema $(\kappa=0.25)$, and poor for chronic anxiety disorder $(\kappa=0.12)$ or chronic sleeping disorder $(\kappa=0.16)$. The results for the 10 most frequent chronic conditions reported by patients are detailed in Table 2 and all results are detailed in Supplemental Table 3.

\section{Agreement Between Patients and GPs on Health Priorities}

We analyzed 153 patient-GP pairs for which both patient and GP wrote a priority list. We collected a total of 519 priorities (reported in a patient list, a GP list, or both lists), corresponding to 81 distinct chronic conditions. A total of 134 (87.6\%) patient-GP pairs had at least 1 matching priority condition in their lists, compared with 19 (12.4\%) with no matching priority condition. For example, 1 patient-GP pair wrote exactly the same priority list: "obesity," "high blood pressure," and "sleep apnea syndrome." In contrast, the following pair was totally discordant given that the patient's list was "allergic rhinitis," "benign prostatic hypertrophy," and "recurrent herpes," and the GP's list was "skin cancer," "dyslipidaemia," and "osteoarthrosis."

The patient's first priority matched the GP's first priority in $68(44.4 \%)$ patient-GP pairs but was not present in $45(29.4 \%)$ of the corresponding GPs' lists.

Among the 519 priority conditions reported by patients or GPs, 157 (30.2\%) were present only in the patient list, 166 (32.0\%) only in the GP list, and 196 $(37.8 \%)$ in both lists. The results for the 10 conditions most frequently listed by patients and GPs are in Figure 1, and all results are detailed in Supplemental Table 4.

\section{DISCUSSION}

In this study, we assessed patient-GP agreement on patients' chronic conditions and health priorities. Concerning disease reporting, our findings varied widely among the diseases. For example, we found substantial agreement between patients and their GPs for high blood pressure but not for chronic anxiety disorder. Some previous studies ${ }^{19,33}$ suggested that disease characteristics may affect patient-GP agreement: participants might be more likely to agree on severe diseases requiring daily treatment or regular monitoring ${ }^{20}$ as compared with more subjective diseases with no clear diagnostic criteria or mild severity. However, GPs might be less aware of the diseases for which they are less involved in the follow-up: in our study, 6 patients reported having macular degeneration, and none of their GPs reported this condition, although the condition is known to greatly affect quality of life. ${ }^{34}$ Indeed, in the French health care system, ophthalmologists are among the specialists that patients can see directly with full coverage without having to consult their attending GP first. Patients might feel no need to tell their GPs about such diseases that are managed mainly by specialists. In contrast, we found higher agreement in our study 
for high blood pressure, diabetes, and hypothyroidism, for which GPs prescribe or renew a regular treatment. These results agree with previous studies comparing disease reporting between patients and physicians. ${ }^{19}$

Concerning prioritization of care, our findings are globally in line with studies suggesting that patients are more likely to prioritize conditions that have consequences on their daily life or that are symptomatic (eg, osteoarthritis) as compared with GPs, who are more likely to prioritize the prevention of disease complications or conditions with poor prognosis (eg, chronic obstructive pulmonary disease). ${ }^{24}$ In our study, GPs failed to elicit what matters most to $29.4 \%$ of patients, which suggests a need for improvement to ensure better alignment between patient and GP perspectives.

\section{Strengths and Limitations}

One strength of our study was the use of a large list of chronic conditions without restricting eligibility to patients with specific diseases. Another strength was the use of an open-ended question as a second step to compare patient and GP priorities, which allowed the participants to use their own words and helped us capture the discrepancies between patient and GP perspectives with a complementary approach.
Our study had some limitations. First, the study was limited by its small sample size and by the GPs being a convenience sample of academic GPs and possibly not representative of all French physicians. The proportion of men was higher in our study than in the French national cohort ${ }^{35}$ as was the proportion of group practices. The latter difference is consistent with previous studies comparing training GPs and French physicians. ${ }^{36}$ However, the participants might have been more motivated and interested in shared decision making and communication with their patients. Second, our recruitment took place in an urban setting, and patients had a high mean level of education. Thus, they may be not representative of the French population, and a high level of education might have improved the patient-GP agreement. ${ }^{33}$ Easier access to specialized care in urban settings might have also led to less GP-coordinated care. Third, regarding the list of conditions, we used the same list for both physicians and patients. Although every effort was made to use simple language, we cannot exclude that some patients could have considered some wording as "medical jargon." We tried to minimize this gap, however, by using the response category "Other." Regarding the ranking of health priorities, because of no validated question

\section{Figure 1. Agreement between patients and general practitioners (GPs) on health priorities $(n=153$ patient-GP pairs).}

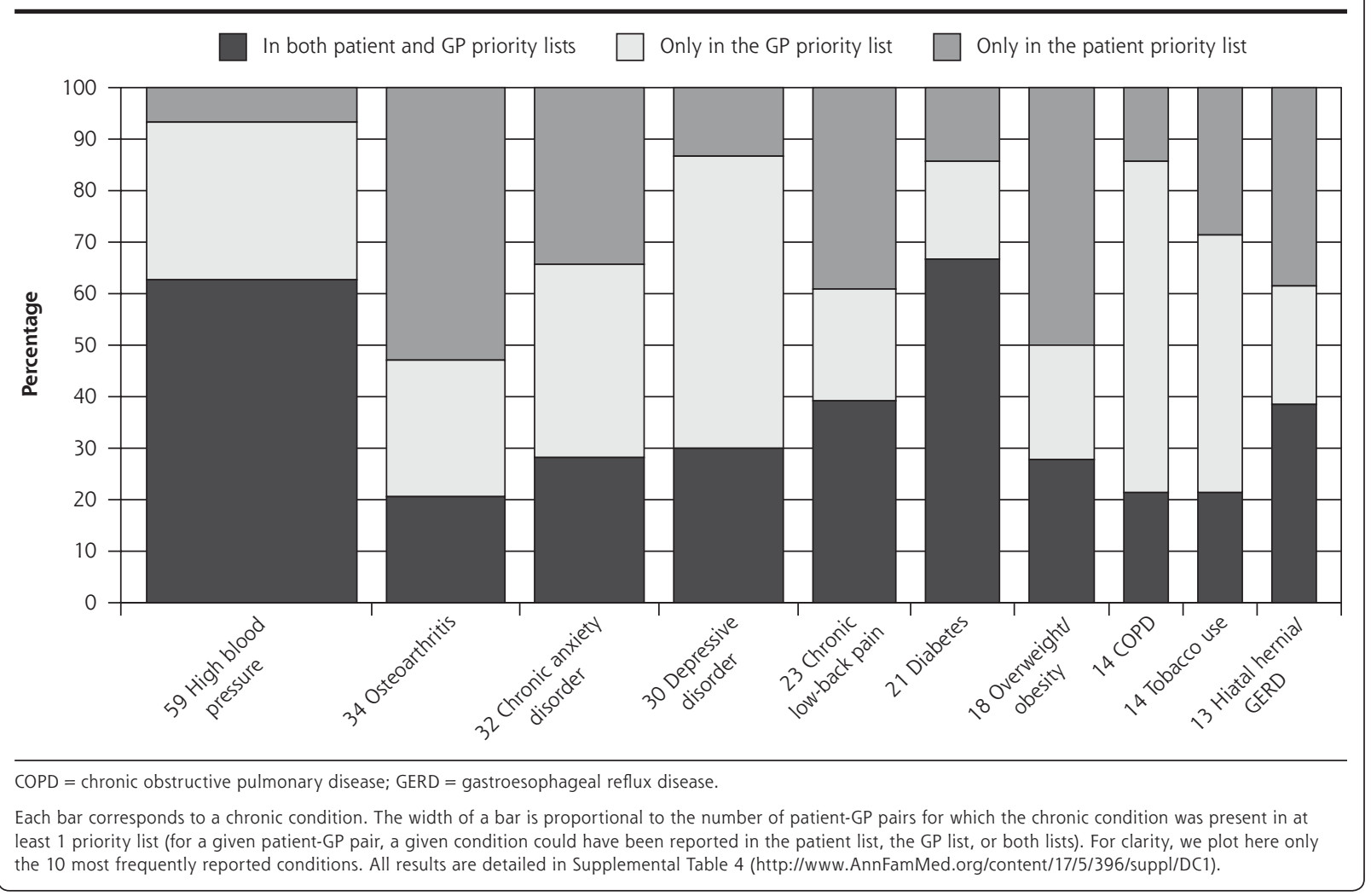

ANNALS OF FAMILY MEDICINE + WWW.ANNFAMMED.ORG + VOL. 17, NO. 5 + SEPTEMBER/OCTOBER 2019 
on this topic, ${ }^{25}$ we chose a pragmatic question focusing on the 3 most important conditions. However, physicians and patients may have interpreted the word important differently. These potential language gaps ${ }^{37}$ might have underestimated the agreement between patients and GPs and could be explored in future studies, which should also pay attention to assessing patients' health literacy. ${ }^{38}$ Indeed, the amount of missing data for this question might be related to poor understanding or participants' difficulty in ranking health problems, even if it could also be explained by respondent burden. Fourth, we may have overestimated patient-GP agreement because the GPs completed the questionnaire before a consultation with a patient, whereas patients completed the questionnaire after the consultation. Fifth, the discrepancies we report should be interpreted carefully because of our small sample size. Moreover, we do not know the extent to which underreporting of specific chronic conditions by GPs corresponds to false-positive patient self-reports (eg, misunderstandings by patients regarding a diagnosis) or false-negative GP reports (eg, potential inaccuracies in the medical record or careless errors) ${ }^{18}$ However, we aimed to assess not whether GPs' records could be considered a criterion standard ${ }^{33}$ nor the prevalence of chronic conditions in France but rather the extent to which patients and their GPs agree. Finally, we used a forced ranking method, although patients may have given equal weight to certain conditions or may have weighted the intervals between rankings differently. Therefore, all the discordant patient-physician pairs should not be interpreted in the same way and might have various clinical implications.

\section{Clinical Implications}

Health care systems face the challenge of an increasing number of people with chronic conditions. Multimorbidity is becoming the norm rather than the exception, with $23 \%$ of patients having 2 or more chronic conditions. ${ }^{1}$ Underreporting of chronic conditions may have direct clinical implications. From the patient's perspective, having a chronic condition requires effective self-care and participation. ${ }^{23}$ Therefore, patients' awareness of their medical condition seems to be critical for optimal treatment. From the GP's perspective, the inability to identify some conditions (eg, chronic anxiety disorder), symptomatic concerns (eg, sleeping disorder), or behaviors (eg, tobacco use) may lead to inadequate management and suboptimal counseling. The substantial poor agreement on health priorities might reflect ineffective 2 -way communication, ${ }_{1}^{17}$ which is a barrier to developing goals in line with patient concerns. ${ }^{7} 16$ However, our study measured only the extent to which patients and physicians shared the same list of priorities and did not explicitly measure the impact of the identified discrepancies on health outcomes or whether physicians are able to identify patients' main concerns. ${ }^{17}$ The latter question is complementary and has been explored in recent studies. ${ }^{25}$ Therefore, our results do not allow us to conclude that patients in discordant patient-GP pairs received inappropriate or less care than they needed.

\section{Future Research}

Our study provides some preliminary results for a small French cohort of patients and GPs. Other studies with larger sample sizes, however, are needed to provide clinically relevant $\mathrm{CIs}$ and confirm our results. Future research should explore the consequences of poor patient-GP agreement on health outcomes. It should also focus on how to achieve efficient personalized communication adjusted to health literacy and how to achieve patient-centered care instead of fragmented disease-centered care in the limited time available for current GP consultations. Indeed, eliciting patient preferences and prioritizing health problems accordingly should be central to every consultation ${ }^{39}$ to set realistic and shared treatment strategies and to achieve minimally disruptive medicine. ${ }^{40}$

\section{Conclusion}

In our study, agreement between patients and their GPs varied widely depending on the diseases reported, and $29.4 \%$ of patients' first priorities did not appear anywhere on the corresponding GPs' lists. Our findings suggest the need for more patient-centered care for patients with various chronic conditions. The pursuit of patient-centered care might require a shift in how our models of care are designed to help physicians and patients build a therapeutic alliance and a better partnership.

To read or post commentaries in response to this article, see it online at http://www.AnnFamMed.org/content/17/5/396.

Submitted September 19, 2018; submitted, revised, February 15, 2019; accepted March 28, 2019.

Key words: patient-centered care; chronic diseases; shared decision making

Acknowledgments: The authors are extremely grateful to all the GPS (in particular Dr Marie Ecollan, Dr Michèle Richemond, Dr François Bloede, Dr Jean-Claude Schwartz, Dr Sophie Olesker, Pr Christian Ghasarossian, Pr Hector Falcoff, Dr Jean-Laurent Thebault, Dr Robert Sourzac, Pr Philippe Jaury, Dr Nicolas de (hanaud) and all the patients who took part in this study. We thank Laura Smales for reviewing the manuscript before submission.

Supplemental materials available at http://www.AnnFamMed. org/content/17/5/396/suppl/DC1. 


\section{References}

1. Barnett K, Mercer SW, Norbury M, Watt G, Wyke S, Guthrie B. Epidemiology of multimorbidity and implications for health care, research, and medical education: a cross-sectional study. Lancet. 2012;380(9836):37-43.

2. Boyd CM, Darer J, Boult C, Fried LP, Boult L, Wu AW. Clinical practice guidelines and quality of care for older patients with multiple comorbid diseases: implications for pay for performance. JAMA. 2005;294(6):716-724

3. Wolff JL, Starfield B, Anderson G. Prevalence, expenditures, and complications of multiple chronic conditions in the elderly. Arch Intern Med. 2002;162(20):2269-2276.

4. Struijs JN, Baan CA, Schellevis FG, Westert GP, van den Bos GA. Comorbidity in patients with diabetes mellitus: impact on medical health care utilization. BMC Health Serv Res. 2006;6:84.

5. Muche-Borowski C, Lühmann D, Schäfer I, et al. Development of a meta-algorithm for guiding primary care encounters for patients with multimorbidity using evidence-based and case-based guideline development methodology. BMJ Open. 2017;7(6):e015478.

6. Boehmer KR, Abu Dabrh AM, Gionfriddo MR, Erwin P, Montori $V M$. Does the chronic care model meet the emerging needs of people living with multimorbidity? A systematic review and thematic synthesis. PLoS One. 2018;13(2):e0190852.

7. Wallace E, Salisbury C, Guthrie B, Lewis C, Fahey T, Smith SM. Managing patients with multimorbidity in primary care. BMJ. 2015;350: h176.

8. Østbye T, Yarnall KS, Krause KM, Pollak KI, Gradison M, Michener $\mathrm{JL}$. Is there time for management of patients with chronic diseases in primary care? Ann Fam Med. 2005;3(3):209-214.

9. Tran VT, Montori VM, Eton DT, Baruch D, Falissard B, Ravaud P. Development and description of measurement properties of an instrument to assess treatment burden among patients with multiple chronic conditions. BMC Med. 2012;10:68.

10. Fortin M, Lapointe L, Hudon C, Vanasse A, Ntetu AL, Maltais D. Multimorbidity and quality of life in primary care: a systematic review. Health Qual Life Outcomes. 2004;2:51.

11. Jordan JL, Ellis SJ, Chambers R. Defining shared decision making and concordance: are they one and the same? Postgrad Med J. 2002;78(921):383-384.

12. Tinetti ME, Fried TR, Boyd CM. Designing health care for the most common chronic condition-multimorbidity. JAMA. 2012;307(23): 2493-2494.

13. Bell RA, Kravitz RL, Thom D, Krupat E, Azari R. Unmet expectations for care and the patient-physician relationship. J Gen Intern Med. 2002;17(11):817-824.

14. Zebiene E, Svab I, Sapoka V, et al. Agreement in patient-physician communication in primary care: a study from Central and Eastern Europe. Patient Educ Couns. 2008;73(2):246-250.

15. Staiger TO, Jarvik JG, Deyo RA, Martin B, Braddock CH. BRIEF REPORT: Patient-physician agreement as a predictor of outcomes in patients with back pain. J Gen Intern Med. 2005;20(10):935-937.

16. Starfield B, Wray C, Hess K, Gross R, Birk PS, D'Lugoff BC. The influence of patient-practitioner agreement on outcome of care. Am J Public Health. 1981;71(2):127-131.

17. Zulman DM, Kerr EA, Hofer TP, Heisler M, Zikmund-Fisher BJ. Patient-provider concordance in the prioritization of health conditions among hypertensive diabetes patients. J Gen Intern Med. 2010; 25(5):408-414.

18. Galenkamp H, Huisman M, Braam AW, Schellevis FG, Deeg DJ. Disease prevalence based on older people's self-reports increased, but patient-general practitioner agreement remained stable, 19922009. J Clin Epidemiol. 2014;67(7):773-780.

19. Hansen H, Schäfer I, Schön G, et al. Agreement between selfreported and general practitioner-reported chronic conditions among multimorbid patients in primary care-results of the MultiCare Cohort Study. BMC Fam Pract. 2014;15:39.
20. Simpson CF, Boyd CM, Carlson MC, Griswold ME, Guralnik JM, Fried LP. Agreement between self-report of disease diagnoses and medical record validation in disabled older women: factors that modify agreement. J Am Geriatr Soc. 2004;52(1):123-127.

21. van den Akker M, van Steenkiste B, Krutwagen E, Metsemakers JF. Disease or no disease? Disagreement on diagnoses between selfreports and medical records of adult patients. Eur J Gen Pract. 2015; 21(1):45-51.

22. Merkin SS, Cavanaugh K, Longenecker JC, Fink NE, Levey AS, Powe NR. Agreement of self-reported comorbid conditions with medical and physician reports varied by disease among end-stage renal disease patients. J Clin Epidemiol. 2007;60(6):634-642.

23. Malik AS, Giamouzis G, Georgiopoulou VV, et al. Patient perception versus medical record entry of health-related conditions among patients with heart failure. Am J Cardiol. 2011;107(4):569-572.

24. Neuner-Jehle S, Zechmann S, Grundmann Maissen D, Rosemann T, Senn O. Patient-provider concordance in the perception of illness and disease: a cross-sectional study among multimorbid patients and their general practitioners in Switzerland. Patient Prefer Adherence. 2017;11:1451-1458.

25. Déruaz-Luyet A, N'Goran AA, Pasquier J, et al. Multimorbidity: can general practitioners identify the health conditions most important to their patients? Results from a national cross-sectional study in Switzerland. BMC Fam Pract. 2018;19(1):66.

26. Classification Committee of the World Organization of Family Doctors (WICC). ICPC-2: International Classification of Primary Care. Oxford, UK: Oxford University Press; 1997.

27. Brown B. Delphi Process: A Methodology Used for the Elicitation of Opinions of Experts. Santa Monica, CA: RAND Corporation; 1968. https://www.rand.org/pubs/papers/P3925.html.

28. Okoli C, Pawlowski SD. The Delphi method as a research tool: an example, design considerations and applications. Information \& Management. 2004;42(1):15-29.

29. O'Halloran J, Miller GC, Britt H. Defining chronic conditions for primary care with ICPC-2. Fam Pract. 2004;21(4):381-6.

30. Shrout PE, Fleiss JL. Intraclass correlations: uses in assessing rater reliability. Psychol Bull. 1979;86(2):420-8.

31. Landis JR, Koch GG. The measurement of observer agreement for categorical data. Biometrics. 1977;33(1):159-74.

32. G. Altman D. Practical Statistics for Medical Research; 2018.

33. Okura Y, Urban LH, Mahoney DW, Jacobsen SJ, Rodeheffer RJ. Agreement between self-report questionnaires and medical record data was substantial for diabetes, hypertension, myocardial infarction and stroke but not for heart failure. J Clin Epidemiol. 2004; 57(10):1096-103.

34. Mitchell J, Bradley C. Quality of life in age-related macular degeneration: a review of the literature. Health Qual Life Outcomes. 2006;4:97.

35. DREES Direction de la recherche des études de l'évaluation et des statistiques. La démographie des médecins (RPPS) 2017. https:// drees.solidarites-sante.gouv.fr/etudes-et-statistiques/open-data/datadrees. Accessed Sep 17, 2018.

36. Bouton C, Leroy O, Huez JF, Bellanger W, Ramond-Roquin A. [Representativeness of general practice university lecturers]. Sante Publique. 2015;27(1):59-67.

37. Safeer RS, Keenan J. Health literacy: the gap between physicians and patients. Am Fam Physician. 2005;72(3):463-468.

38. Heijmans M, Waverijn G, Rademakers J, van der Vaart R, Rijken M. Functional, communicative and critical health literacy of chronic disease patients and their importance for self-management. Patient Educ Couns. 2015;98(1):41-48.

39. Muth C, van den Akker M, Blom JW, et al. The Ariadne principles: how to handle multimorbidity in primary care consultations. BMC Med. 2014;12:223.

40. May C, Montori VM, Mair FS. We need minimally disruptive medicine. BMJ. 2009;339:b2803. 